$$
\operatorname{Pontifícia~}_{\substack{\text { do Rio de Janeiro } \\ \text { Uneridade }}}
$$

João Eduardo Chagas Sobral

\begin{abstract}
A Linguagem Fotográfica na Formação do Designer em um Ambiente de Convergência Tecnológica
\end{abstract}

Tese de Doutorado

Tese apresentada ao Programa de Pós-graduação em Design do Departamento de Artes \& Design da PUC-Rio como parte dos requisitos parciais para obtenção do título de Doutor em Design.

Orientadora: Jackeline Farbiarz Co-orientadora: Izabel Maria de Oliveira

Rio de Janeiro

Agosto de 2011 


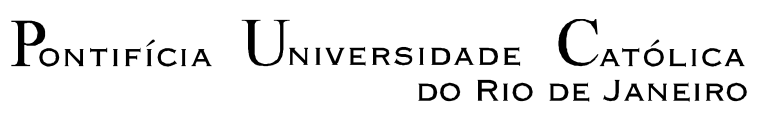

DO RIO DE JANEIRO

João Eduardo Chagas Sobral

\section{A linguagem fotográfica na formação do designer em um ambiente de convergência tecnológica}

Tese apresentada como requisito parcial para obtenção do grau de Doutor pelo Programa de Pós-Graduação em Design do Departamento de de Artes \& Design do Centro de Teologia e Ciências Humanas. Aprovada pela Comissão Examinadora abaixo assinada.

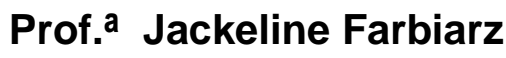
Orientador

Departamento de Artes \& Design - PUC-Rio

Prof. Izabel Maria de Oliveira

Co-orientador

Departamento de Artes \& Design - PUC-Rio

Prof. - Vera Nojima

Departamento de Artes \& Design - PUC-Rio

Prof. ${ }^{\text {a Luiza Novaes }}$

Departamento de Artes \& Design - PUC-Rio

Prof. Rodrigo de Almeida Bastos Universidade Federal de Santa Catarina-UFSC

Prof. Alexandre Farbiarz Universidade Federal Fluminense - UFF

Prof.. Denise Berruezo Portinari Coordenadora Setorial do Centro de Teologia e Ciências Humanas - PUC- Rio

Rio de Janeiro, agosto de 2011 
Todos os direitos reservados. É proibida a reprodução total ou parcial do trabalho sem autorização da universidade, do autor e do orientador.

\section{João Eduardo Chagas Sobral}

Graduado em Comunicação Visual pela Universidade Federal de Pernambuco em 1983 e Mestrado em Educação pela Fundação Universidade Regional de Blumenau em 2002. Chefe do Departamento de Design e professor titular da Universidade da Região de Joinville - UNIVILLE.

Ficha Catalográfica

Sobral, João Eduardo Chagas

A linguagem fotográfica na formação do designer em um ambiente de convergência tecnológica / João Eduardo Chagas Sobral ; orientadora: Jackeline Farbiarz ; co- orientadora: Izabel Maria de Oliveira. 2011.

145 f. : il.(color.) ; $30 \mathrm{~cm}$

Tese (doutorado)-Pontifícia Universidade Católica do Rio de Janeiro, Departamento de Artes e Design, 2011.

Inclui bibliografia

1. Artes e design - Teses. 2. Fotografia. 3. Linguagem fotográfica. 4. Formação do designer. 5. Convergência. I Farbiarz, Jackeline. II. Oliveira, Izabel Maria de. III. Pontifícia Universidade Católica do Rio de Janeiro. Departamento de Artes e Design. IV. Título. 


\section{Agradecimentos}

A minha orientadora Professora Jackeline Farbiarz pelo estímulo, parceria e competência na condução deste trabalho.

A minha co-orientadora Izabel Maria de Oliveira e todos os professores do doutorado que proporcionaram constantes reflexões críticas e enriquecedoras.

A FAPESC e à UNIVILLE, pelos auxílios concedidos para a realização desta pesquisa.

Aos meus pais e irmãos, pelo constante empenho e valorização à educação.

À Anna Cavalcanti, minha esposa, pela ajuda, dedicação e compreensão.

A colega e irmã Marli Everling pela parceria, estímulo e troca.

A todos os meus colegas da Univille, Udesc e PUC- Rio pela agradável convivência durante o doutorado. 


\section{Resumo}

Sobral, João Eduardo Chagas; Farbiarz, Jackeline (Orientadora). A linguagem fotográfica na formação do designer em um ambiente de convergência tecnológica. Rio de Janeiro, 2011. 145p. Tese de Doutorado - Departamento de Artes \& Design, Pontifícia Universidade Católica do Rio de Janeiro.

Esta tese parte da premissa que os ambientes de convergência, construídos a partir da tecnologia digital, estão afetando a disciplina de fotografia nos cursos de Design e, por conseqüência, interferindo nos processos de aprendizagem e na formação do designer. Esta investigação visa compreender o que os professores entendem por disciplina de fotografia, e, apropriando-se das novas tecnologias, que estratégias eles usam para disseminar o conhecimento entre os alunos. A pesquisa iniciou com uma pequena digressão sobre a fotografia na contemporaneidade e sobre a linguagem fotográfica, além de um levantamento sobre a disciplina de fotografia nos cursos de Design da PUC- Rio e da Univille, analisando as matrizes curriculares, ementas e percursos metodológicos. Foram também realizadas entrevistas com os professores que ministram esta disciplina, com o objetivo de colher e categorizar dados, os quais foram submetidos à técnica Análise do Conteúdo sob o enfoque dos lugares da imagem, contribuindo com a percepção sobre o papel que a fotografia desempenha em um diferente cenário tecnológico e na formação do designer nos cursos de Design da PUC- Rio e da Univille.

\section{Palavras- chave}

Fotografia, linguagem fotográfica, formação do designer, convergência. 


\section{Abstract}

Sobral, João Eduardo Chagas; Farbiarz, Jackeline (Advisor). The photographic language in the designer training in an environment of technological convergence. Rio de Janeiro, 2011. 145p. Doctoral Thesis - Departamento de Artes \& Design, Pontifícia Universidade Católica do Rio de Janeiro.

This thesis assumes that the environments of convergence, constructed from digital technology, are affecting the discipline of Photography courses in design and consequently interfering in the processes of learning and training of the designer. This research aims to understand what teachers mean by the discipline of Photography, and appropriating the new technologies, what strategies they use to disseminate knowledge among students. The research began with a small digression on contemporary photography and the photographic language, and a survey of the discipline of Photography in the courses of Design at PUC-Rio and Univille analyzing the curricular content, menus and methodological tracks. We also conducted interviews with teachers who teach this course in order to collect and categorize data, which were submitted to the content analysis technique from the standpoint of image sites, contributing to the perception of the role that photography plays in a different technological scenery and in the designer training in the courses of Design at PUC-Rio and Univille.

\section{Keywords}

Photography, photographic language, design training, convergence 


\section{Sumário}

1 Introdução

2 Pequena digressão sobre a fotografia na contemporaneidade 20

2.1 A tecnologia digital e a fotografia 20

2.2 A cultura da convergência e a fotografia 29

2.3 Pontos a considerar 38

3 Pequena Digressão sobre Linguagem Fotográfica e Educação $\quad 40$

3.1 A fotografia e a Linguagem Fotográfica 40

3.2 A linguagem Fotográfica e a Educação 54

3.3 Pontos a considerar 64

4 Histórico, Percurso Metodológico e Análise das Entrevistas 66

4.1 Introdução 66

4.2 Histórico do Curso de Design da PUC- Rio e da Univille 66

4.2.1 Projetos Pedagógicos: Conceituação 66

4.2.2 Perfil do Egresso 67

4.2.2.1 Perfil do Egresso do Curso de Design da PUC- Rio 68

4.2.2.2 Perfil do Egresso no Curso de Design da Univille 69

4.2.3 Considerações sobre os Perfis Profissiográficos 70

4.3 Matrizes Curriculares e Ementas 70

4.3.1 Considerações sobre as Disciplinas de Fotografia 72

4.4 Percurso Metodológico 73

4.4.1 Amostragem $\quad 74$

4.4.2 Instrumento de Coleta de Dados 74

4.4.3 Tratamento dos Dados 77 
$\begin{array}{ll}\text { 4.4.4 Procedimento de Categorização } & 77\end{array}$

4.4.5 Representação dos Dados 85

4.4.5.1 Corpus Secundário. PUC- Rio 85

4.4.5.2 Corpus Secundário. Univille 86

$\begin{array}{ll}\text { 4.4.5.3 Corpus Principal. PUC-Rio } & 87\end{array}$

$\begin{array}{ll}\text { 4.4.5.4 Corpus Principal. Univille } & 93\end{array}$

4.5 Análise da Pesquisa 98

4.5.1 Mudanças Tecnológicas (MT) 98

4.5.1.1 Mudança tecnológica e a prática fotográfica nos cursos de design

104

4.5.1.2 Mudanças da relação da disciplina de fotografia nos cursos $\begin{array}{ll}\text { de design } & 107\end{array}$

4.5.1.3 A fotografia e os softwares de tratamento de imagens 109

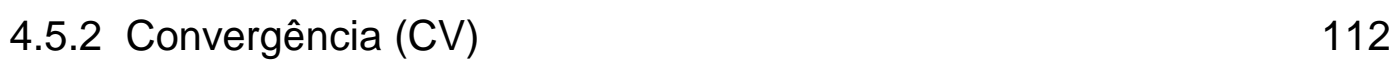

4.5.2.1 O conteúdo programático e a câmara fotográfica no celular 115

4.5.2.2 O ensino da fotografia e a convergência tecnológica 117

$\begin{array}{ll}\text { 4.5.3 Conteúdo Programático (CP) } & 119\end{array}$

4.5.3.1 Os conteúdos ministrados nas disciplinas de fotografia 121

4.5.3.2 A bibliografia indicada no programa das disciplinas de fotografia 124

4.5.3.3 As avaliações na disciplina de fotografia 125

$\begin{array}{ll}\text { 4.5.4 Formação do Designer (FD) } & 126\end{array}$

4.5.4.1 $\mathrm{O}$ ensino da linguagem fotográfica amplia a visão de mundo dos alunos

4.5.4.2 A disciplina de fotografia na formação do designer 129

$\begin{array}{lr}\text { 4.6 Pontos a considerar } & 130\end{array}$

5 Conclusão 135

6 Referências Bibliográficas 142 


\section{Lista de figura}

Figura 1: Sebastião Salgado. Subindo a Serra Pelada, Brasil, 1986

Figura 2: Marco Scisetti, Media Room, november 200723

Figura 3: Robert Doisneau Traume eisnes Tatowierten. $1952 \quad 26$

Figura 4: Fotografia produzida com câmera de celular. JORDI V.

POU. Galeria do El Pais.com

Figura 5: Tony Garcia. Young woman with head between internet address on subway car wall

Figura 6: GPS RA - Acesso 27/06/2011

http://itnewsbr.wordpress.com/?s=realidade+aumentada

Figura 7: Serge Moreno Cohen. Jasper Johns, 198638

Figura 8: Ilse Bing. Selbsportrat in Spiegeln, 1931

Figura 9: Life Magazine Cover November 10, 1947.

Photo by John Florea/Time \& Life Pictures/Getty Images

Figura 10: Publicidade da Mitra Imaging System.

Communication arts $\mathrm{N}^{\circ} 38,1997$

Figura 11: João Sobral, sem título. Barcelona, 2000

Figura 12: Serge Moreno Cohen. Richard Avedon, 1994

Figura 13: Man Ray. Jean Cocteau, 1922 


\section{Lista de Quadros}

4.3 - Quadro 1 - Panorama da disciplina de fotografia nas habilitações em Comunicação Visual e Projeto de Produto da PUC- Rio.

4.3 - Quadro 2 - Panorama da disciplina de fotografia na habilitação em Comunicação Visual da Univille.

4.3 - Quadro 3 - Panorama da disciplina de fotografia na habilitação em Projeto de Produto da Univille.

4.4.4 - Quadro 5 - Relação unidades de contexto e as perguntas da entrevista

4.4.4 - Quadro 6 - Correspondências entre categorias, perguntas, unidades de contexto e número de unidades de registro.

4.4.4 - Quadro 7 - Relação categoria, unidade de contexto e perguntas da entrevista.

4.4.5.1 - Quadro 8 - Primeira relação unidades de contexto e unidades de registro para o professor $A$ no corpus secundário da PUC- Rio.

4.4.5.1 - Quadro 9 - Segunda relação unidades de contexto e unidades de registro para o professor $A$ no corpus secundário da PUC- Rio.

4.4.5.1 - Quadro 10 - Primeira relação unidades de contexto e unidades de registro para o professor $B$ no corpus secundário da PUC- Rio.

4.4.5.1 - Quadro 11 - Segunda relação unidades de contexto e unidades de registro para o professor $\mathrm{A}$ no corpus secundário da PUC- Rio.

4.4.5.2 - Quadro 12 - Primeira relação unidades de contexto e unidades de registro para o professor $\mathrm{A}$ no corpus secundário da Univille.

4.4.5.2 - Quadro 13 - Segunda relação unidades de contexto e unidades de registro para o professor $A$ no corpus secundário da Univille.

4.4.5.2 - Quadro 14 - Primeira relação unidades de contexto e unidades de registro para o professor $\mathrm{B}$ no corpus secundário da Univille.

4.4.5.2 - Quadro 15 - Segunda relação unidades de contexto e unidades de registro para o professor $B$ no corpus secundário da Univille. 
4.4.5.3 - Quadro 16 - Relação entre unidade de contexto 01, unidades de registro e frequência na PUC- Rio.

4.4.5.3 - Quadro 17 - Relação entre unidade de contexto 02, unidades de registro e frequência na PUC- Rio.

4.4.5.3 - Quadro 18 - Relação entre unidade de contexto 03, unidades de registro e frequência na PUC- Rio.

4.4.5.3 - Quadro 19 - Relação entre unidade de contexto 04, unidades de registro e frequência na PUC- Rio.

4.4.5.3 - Quadro 20 - Relação entre unidade de contexto 05, unidades de registro e frequência na PUC- Rio.

4.4.5.3 - Quadro 21 - Relação entre unidade de contexto 06, unidades de registro e frequência na PUC- Rio.

4.4.5.3 - Quadro 22 - Relação entre unidade de contexto 07, unidades de registro e frequência na PUC- Rio.

4.4.5.3 - Quadro 23 - Relação entre unidade de contexto 08, unidades de registro e frequência na PUC- Rio.

4.4.5.3 - Quadro 24 - Relação entre unidade de contexto 09, unidades de registro e frequência na PUC- Rio.

4.4.5.3 - Quadro 25 - Relação entre unidade de contexto 10, unidades de registro e frequência na PUC- Rio.

4.4.5.3 - Quadro 26 - Relação entre unidade de contexto 11, unidades de registro e frequência na PUC- Rio.

4.4.5.3 - Quadro 27 - Relação entre unidade de contexto 12, unidades de registro e frequência na PUC- Rio.

4.4.5.3 - Quadro 28 - Relação entre unidade de contexto 13, unidades de registro e frequência na PUC- Rio.

4.4.5.4 - Quadro 29- Relação entre unidade de contexto 01, unidades de registro e frequência na Univille.

4.4.5.4 - Quadro 30- Relação entre unidade de contexto 02, unidades de registro e frequência na Univille.

4.4.5.4 - Quadro 31- Relação entre unidade de contexto 03, unidades de registro e frequência na Univille

4.4.5.4 - Quadro 32- Relação entre unidade de contexto 04, unidades de registro e frequência na Univille.

4.4.5.4 - Quadro 33- Relação entre unidade de contexto 05, unidades de registro e frequência na Univille.

4.4.5.4 - Quadro 34- Relação entre unidade de contexto 06, 
unidades de registro e frequência na Univille.

4.4.5.4 - Quadro 35- Relação entre unidade de contexto 07, unidades de registro e frequência na Univille.

4.4.5.4 - Quadro 36- Relação entre unidade de contexto 08, unidades de registro e frequência na Univille.

4.4.5.4 - Quadro 37- Relação entre unidade de contexto 09, unidades de registro e frequência na Univille.

4.4.5.4 - Quadro 38- Relação entre unidade de contexto 10, unidades de registro e frequência na Univille.

4.4.5.4 - Quadro 39- Relação entre unidade de contexto 11, unidades de registro e frequência na Univille.

4.4.5.4 - Quadro 40- Relação entre unidade de contexto 12, unidades de registro e frequência na Univille.

4.4.5.4 - Quadro 41- Relação entre unidade de contexto 13, unidades de registro e frequência na Univille. 
Os espelhos estão cheios de gente.

Os invisíveis nos vêem.

Os esquecidos se lembram de nós.

Quando nos vemos, os vemos.

Quando nos vamos, se vão?

Eduardo Galeano, Espelhos

Uma história quase universal 